\title{
Analysis of the Coupling Path of Qi Culture and Regional Economy
} Wen $\mathbf{L i}^{*}$

Zibo Vocational Institute, Zibo City 255000, Shandong Province, China. E-mail: 66674254@qq.com

\begin{abstract}
At present, local culture is becoming more and more important in the developing process of national economy and society, increasing the significance of the development and reconstruction of local culture in various places as well. Local culture can promote the brand building, tourism and economic development. In the long history from the Spring and Autumn Period to the Qin and Han Dynasties and till now, Qi culture has been eclectic, becoming a symbol of Chinese culture, and forming a unique spiritual characteristic of self-improvement, kindness, virtue and wisdom. This paper analyzes the coupling path of Qi culture and regional economy.
\end{abstract}

Keywords: Qi Culture; Regional Economy; Coupling Path; Analysis

\section{Introduction}

In the long history from the Spring and Autumn Period to the Qin and Han Dynasties and till now, Qi culture has been eclectic, becoming an important part and even a symbol of Chinese culture, and forming a unique spiritual characteristic of self-improvement, virtue, kindness and wisdom. For a long time, Qi culture has deeply influenced the thoughts and lives of people living in Qilu (regions in Shandong Province). In recent years, the interaction between the cultural industry and the regional economy has received extensive attention from scholars ${ }^{[1]}$. The views of the cultural industry and the regional economy influencing and promoting each other have been generally recognized by domestic and foreign scholars. In order to achieve common prosperity and promote the comprehensive and harmonious development of society, it is necessary to promote the coordinated development of Qi culture and regional economy.

\section{The core concepts of Qi Culture}

Culture is a concept that is difficult to be defined and generalized scientifically and accurately. So far, there have been more than 200 definitions of culture in academia. According to Marx and Engels, culture has a very broad connotation, who believed that culture was one of the superstructures determined by the economic foundation and a form of social ideology. The development of culture is not synchronized with the change of economic foundation. The academic community divides human culture into four cultural systems including the Chinese cultural system, while there are several major sub-cultural systems within the Chinese cultural system. Furthermore, the Chinese cultural system can be divided into eight cultural circles according to the regional culture and four major cultural areas, and Qi culture is a part of the eight major cultures and is closely linked to Lu culture.

Qi culture is derived from the Dawenkou culture, Longshan culture and Yueshi culture of the Neolithic Age, and the Dongyi culture provides an important prehistoric cultural foundation for the development of Qi culture. Qi Culture started from the establishment of Qi State by Jiang Shang, and with the development of long-term history and cultural

Copyright (C) 2020 Wen Li

doi: $10.18282 / \mathrm{ff} . \mathrm{v} 9 \mathrm{i} 2.891$

This is an open-access article distributed under the terms of the Creative Commons Attribution Non-Commercial License

(http://creativecommons.org/licenses/by-nc/4.0/), which permits unrestricted non-commercial use, distribution, and reproduction in any medium,

provided the original work is properly cited. 
accumulation, it has formed its own set of cultural systems. In addition, it has strong cultural flexibility and compatibility, and in terms of political principles, "Jian Qili" pays more attention to hegemony and magic. During the Warring States Period, Duke Huan of Qi founded the Jixia Academy of Higher Education. During the glorious period, there were hundreds of students in the schools, where they communicated and learned from each other. With the development of the times, the Chinese feudal dynasty developed to a peak in the period of Emperor Wu of Han Dynasty, with the unity of culture required by the centralization of feudal rule. Under the impetus of this trend, Dong Zhongshu put forward the idea of "deposing other schools of thoughts and respecting Confucianism alone". The deeper integration of Qi culture and Lu culture has formed a cultural system of "integration of benevolence and wisdom". Beginning in the Western Zhou Dynasty, it was passed down to modern times, forming its own characteristics that are different from other regional cultures. After more than two thousand years of historical development, Qi culture has evolved from the ancient Western Zhou Dynasty and has developed into a national spirit of time and space, various customs, and profound literature and art, etc., all of which are currently being passed on and carried forward ${ }^{[2]}$.

\section{The coupling path of Qi culture and regional economy}

\subsection{Transformation of thoughts}

The concept of regional culture has always subtly influenced the subject of regional development who uses it as a carrier and intermediary. At the micro level, it affects the institutional arrangement, employment mechanism, and layout form of the market subject of enterprises; at the macro level, it affects regional economic activity, innovation and comprehensive power. The unification, interaction and coupling of these two levels form an economic model with a strong regional cultural brand. To a certain extent, the lack of cultural innovation and the lagging of conservative concepts are important reasons for economic lag. The backwardness of cultural concepts leads to insufficiency in construction investment, coordination of departments, policy guidance, and system innovation, which seriously hinders the development of regional economy. It should start from changing thoughts. Based on the regional differences of cultural concepts, exploration, description, and analysis of regional group concepts and cultural psychological structures should be carried out to promote strengths and avoid weaknesses; internal and external exchanges should be promoted through improving local transportation; in addition, carrying out system innovation, strengthening policy guidance, and developing the market can actively promote the change of thoughts; and even the first change of ideology and concepts can play a pioneering role.

\subsection{Organic combination}

The concept of regional culture has an important impact on the regional economy, and in turn, the regional economy has an all-round impact on culture through its material basis. As Althusser said, due to the formation of mass consumer society, the system of commodities and objects surrounding people more and more plays the ideological functions, so that the effective process of contemporary ideology is mainly achieved by daily consumer behavior. As the ever-growing knowledge and technology, as well as the problems and the ideas formed by it, continue to the present and affect daily life, then the historical unification of the two is required. Only when the logic of the two is unified, and through the coupling and amplification of the regional system, can a joint force be formed, which can actively promote the evolution and sustainable development of the regional system. Both the regional culture and economy should be paid attention to, so that economic development can be achieved without the cost of cultural decadence, or the loss of spiritual homes. Then a healthy interaction between economy and culture can be realized. In the coupling of Qi culture and regional economy, cultural construction should be gradually achieved with powerful measures, so that cultural construction can be put into practice, such as the development of cultural activities, the improvement of cultural facilities, and the increase in investment in education. Other approaches include forming a cultural atmosphere, thickening the cultural background, optimizing the cultural environment and enriching the cultural content, thus changing the customs and concepts in a subtle manner. The quantitative changes will finally bring about qualitative 
changes.

\subsection{Multiple interactions}

There is a strong regional cultural flavor in the formation, connotation and characteristics of the development model of regional economy. It can be said that different development models are the reaction of different systems and the result of the active choice of different cultures. In fact, in the modern society, science and technology are the primary productive forces, which greatly affects the development model in the long run. However, in a specific space-time environment, regional culture has a very important impact on economic modernization for specific regions. The regional model of economic modernization has close internal logical connections and consistency with the historical traditions and cultural backgrounds of different regions. Along with changes over time, Qi culture should also continue to develop and innovate, so as to promote the sustainable development of the region through integration effects and transcendental functions. In specific practice, attention should be paid to the combination of major and minor traditions, and the integration of cultures in different regions. At the same time, it is necessary to learn from and absorb foreign cultures, especially the essence of Western industrial civilization, learn the experience of industrialization in developed countries, and promote the development of China's culture. The new integration of China has laid the cultural foundation for China's economic development.

\subsection{Principles of system innovation}

From a cultural point of view, the so-called regional economic model is produced under the background of a certain macroeconomic policy in a specific historical period. It is the result of the active choice of regional development subjects and systematic innovation. It is constantly changing and infiltrating in the regional practice, and gradually a development path with regional characteristics is formed. The regional economic model is of regional characteristics, timing opportunities, development transmutation, multiple paths, and coupling and interaction. To a certain extent, regional development is the result of the coupling effect of various factors, so it should be systematically innovative to form a coupling force. Among them, idea innovation is the basis of active production and activity. Institutional innovation and management innovation are the deepening and practice of idea innovation. Meanwhile, idea change not only clears ideological obstacles for economic development, but also brings about potential advantages. Only through specific market construction and structural adjustment, can the advantages be transformed into economic advantages and actual productivity. Therefore, the change of concept is the premise, institutional innovation is the core, policy guidance is the key, and economic structural adjustment is the goal.

\section{Conclusion}

Culture and economy have always been interdependent and the new economy has strengthened this trend. With the deepening of China's reform and opening up, the role of regional cultural concepts in society and economy has also attracted attention $^{[3]}$. The power of culture lies in its slow permeability, as it always affects the regional development subject in a subtle way, and affects all links of social and economic development through the organization and integration function of the development subject, thus forming the foundation of regional economic development. Through intermediary conduction, penetration magnification, and participation in the regional economic cycle, Qi culture has become an important factor for the sustainable development of the regional economy.

\section{References}

1. Xiao P. Research on the coupling and coordinated development of culture and tourism industry: Taking Jiangsu Province as an example (in Chinese) [MSc thesis]. Nanjing: Nanjing Normal University; 2015. p. 1-3.

2. Jiang B. Analysis of the coupling model of cultural and ecological tourism and regional economy: Taking the cultural and ecological tourism based on The Book of Songs and the construction of the Central Plains Economic Region (in Chinese). Journal of Anyang Normal University 2017; (1): 34-40. doi: 10.3969/j.issn.1671-5330.2017.01.011. 
3. Hu X. Research on the coupling of regional cultural resources and tourism economy: Taking Jiangsu Province as an example. Nanjing: Southeast University Press; 2015. p. 200-204. 